University of Nebraska - Lincoln

DigitalCommons@University of Nebraska - Lincoln

2-2005

\title{
The Perpendicular Magnetic Anisotropy of CoPt/Au Multilayer Films
}

\author{
T. Yokota \\ University of Nebraska - Lincoln \\ Lei Gao \\ University of Kansas, Igao3@unl.edu \\ R. Zhang \\ University of Nebraska - Lincoln \\ Leighann Nicholl \\ University of Nebraska - Lincoln, Inicholl2@unl.edu
}

M. L. Yan

University of Nebraska - Lincoln

See next page for additional authors

Follow this and additional works at: https://digitalcommons.unl.edu/physicsliou

Part of the Physics Commons

Yokota, T.; Gao, Lei; Zhang, R.; Nicholl, Leighann; Yan, M. L.; Sellmyer, David J.; and Liou, Sy-Hwang, "The Perpendicular Magnetic Anisotropy of CoPt/Au Multilayer Films" (2005). Si-Hwang Liou Publications. 99. https://digitalcommons.unl.edu/physicsliou/99

This Article is brought to you for free and open access by the Research Papers in Physics and Astronomy at DigitalCommons@University of Nebraska - Lincoln. It has been accepted for inclusion in Si-Hwang Liou Publications by an authorized administrator of DigitalCommons@University of Nebraska - Lincoln. 


\section{Authors}

T. Yokota, Lei Gao, R. Zhang, Leighann Nicholl, M. L. Yan, David J. Sellmyer, and Sy-Hwang Liou 
Published in Journal of Magnetism and Magnetic Materials 286 (February 2005), pp. 301-305; in “Proceedings of the 5th International Symposium on Metallic Multilayers"; doi 10.1016/j.jmmm.2004.09.142 Copyright (C 2004 Elsevier B.V. Used by permission. http://www.sciencedirect.com/science/journal/03048853

Published online November 4, 2004.

\title{
The perpendicular magnetic anisotropy of $\mathrm{CoPt} / \mathrm{Au}$ multilayer films
}

\author{
T. Yokota, L. Gao, R. Zhang, L. Nicholl, M. L. Yan, D. J. Sellmyer, and S. H. Liou
}

Department of Physics and Astronomy and Center for Materials Research and Analysis, University of Nebraska-Lincoln, Lincoln, Nebraska 68588-0111, USA

Corresponding author - S. H. Liou, email sliou@unl.edu

\begin{abstract}
We have studied the magnetic properties of $\mathrm{Au}(2 \mathrm{~nm}) / \mathrm{Co}_{50} \mathrm{Pt}_{50}(3 \mathrm{~nm}) / \mathrm{Au}(2 \mathrm{~nm})$ multilayer films prepared on amorphous $\mathrm{Al}_{2} \mathrm{O}_{3} / \mathrm{Si}$ and $\left(\begin{array}{lll}0 & 0 & 1\end{array}\right) \mathrm{MgO}$ substrates. The as-deposited films on both substrates are magnetically soft with an FCC structure and exhibit a perpendicular anisotropy. After annealing at $500{ }^{\circ} \mathrm{C}$, the sample on the $\mathrm{Al}_{2} \mathrm{O}_{3} / \mathrm{Si}$ substrate has become magnetically isotropic but the sample on the $\mathrm{MgO}$ substrate still has perpendicular anisotropy with FCT structure. This film deposited on the MgO substrate did not show a strong perpendicular anisotropy due to the diffusion of the Au and the (111) nucleation of initial Au layer. We can obtain a perpendicular anisotropy in the multilayer films without an initial Au layer on a $\left(\begin{array}{ll}0 & 0\end{array}\right) \mathrm{MgO}$ substrate. After annealing at $400{ }^{\circ} \mathrm{C}$, these films have $\mathrm{L} 1_{0}$ phase with $\left(\begin{array}{lll}0 & 0 & 1\end{array}\right)$ texture and strong perpendicular anisotropy.
\end{abstract}

Keywords: $\mathrm{CoPt}, \mathrm{L1}_{0}$ phase, Ordering temperature, Perpendicular anisotropy

\section{Introduction}

Binary alloys such as CoPt and FePt with an $\mathrm{L1}_{0}$-ordered structure have been attractive as ultrahigh-density magnetic recording media, permanent magnets and other applications [1-10] because of their magnetocrystalline anisotropy (on the order of $10^{7} \mathrm{ergs} / \mathrm{cm}^{3}$ ), and a relatively high saturation magnetization $\left(M_{s}=800 \mathrm{emu} /\right.$ $\left.\mathrm{cm}^{3}\right)[5,6]$. In general, an annealing process above $600{ }^{\circ} \mathrm{C}$ is necessary to obtain the $\mathrm{L} 1_{0}$-ordered structure [7-10]. This temperature is undesirable for the manufacturing process. Hence, there have been many attempts to reduce the ordering temperature. Adding a third element such as $\mathrm{Sn}, \mathrm{Pb}, \mathrm{Sb}, \mathrm{Bi}, \mathrm{Ag}, \mathrm{B}, \mathrm{Cu}$, or $\mathrm{Zr}$ into these alloys was reported to be effective for reducing the ordering temperature [11-16]. We also re- 
ported the effect of a Au spacer layer for the transition to the $\mathrm{L}_{0}$ phase. The $\mathrm{L} 1_{0}$ phase in the system of [CoPt/Au] films was observed at $400{ }^{\circ} \mathrm{C}$. This ordered structure easily became the (1 111$)$ texture, which has a random $c$-axis orientation. For perpendicular magnetic recording applications, it is also desirable for the easy axis of magnetization in the films to orient perpendicular to the plane. For example, CoPt film should have a $\left(\begin{array}{lll}0 & 0 & 1\end{array}\right)$ texture. In general, different kinds of seed layers such as $\mathrm{MgO}, \mathrm{Ag}$, and Mo are effective in controlling the crystal orientation [17-20]. Furthermore, a multilayered structure also produced perpendicular anisotropy [21-23].

In this article, we investigate the influence of crystal orientation and $\mathrm{L}_{0}$ phase formation on the perpendicular anisotropy of [Au $(2 \mathrm{~nm}) /$ $\left.\mathrm{Co}_{50} \mathrm{Pt}_{50}(3 \mathrm{~nm}) / \mathrm{Au}(2 \mathrm{~nm})\right]_{7}$ multilayer structured films by preparing two sets of samples. The first set used two different substrates, amorphous $\mathrm{Al}_{2} \mathrm{O}_{3} / \mathrm{Si}$ and $\left(\begin{array}{lll}0 & 0 & 1\end{array}\right) \mathrm{MgO}$, to show their influence on crystal growth. The second set was prepared on $\mathrm{MgO}$ to investigate the influence of the Au initial layer on the crystal orientation of these films.

\section{Experiment}

$\mathrm{Au}(2 \mathrm{~nm}) / \mathrm{CoPt}(3 \mathrm{~nm}) / \mathrm{Au}(2 \mathrm{~nm})$ multilayer films (number of CoPt layers is 7 and total thickness of CoPt is $21 \mathrm{~nm}$ ) were prepared on an $\mathrm{Al}_{2} \mathrm{O}_{3} / \mathrm{Si}$ substrate and a $\left(\begin{array}{lll}0 & 0 & 1\end{array}\right) \mathrm{MgO}$ substrate using a conventional direct current magnetron sputtering system. A CoPt alloy with 50:50 atomic ratios was used as a target. The base pressure before introducing the Ar gas was $1.0 \times 10^{-7}$ Torr and the gas pressure during the deposition was 5-10 mTorr. The deposition rate was $0.5 \AA$ /s for CoPt and $0.8 \AA$ / s for Au, respectively. The growth temperature was changed from room temperature (RT) to $350^{\circ} \mathrm{C}$. We annealed the samples at $350-500{ }^{\circ} \mathrm{C}$ for $10 \mathrm{~h}$ in a 3:1 Ar: $\mathrm{H}_{2}$ atmosphere. The magnetic properties of the sample were measured at RT using an Alternating Gradient Force Magnetometer and Superconducting Quantum Interference Device Magnetometer. The structural analysis of the films was performed with an X-ray diffractometer (XRD) using $\mathrm{Cu} \mathrm{K}_{\alpha}$ radiation.

\section{Results and discussion}

Figure 1 shows magnetization curves $(M-H)$ for $\mathrm{Au} / \mathrm{CoPt} / \mathrm{Au}$ layer films deposited at RT on (a) amorphous $\mathrm{Al}_{2} \mathrm{O}_{3} / \mathrm{Si}$ and (b) $\left(\begin{array}{lll}0 & 0 & 1\end{array}\right) \mathrm{MgO}$ substrates. Both films show a perpendicular magnetic anisotropy. The magnetic anisotropy constants $\left(K_{\mathrm{u}}\right)$, evaluated using the magnetization curve, are $2.5 \times 10^{5}$ and $4.0 \times 10^{5} \mathrm{erg} / \mathrm{cm}^{3}$, respectively. Since both films show almost the same magnetic anisotropy, this magnetic anisotropy is suggested to be caused by the multi-layered structure [21]. In order to get an $\mathrm{L1}_{0}$ phase formation, these samples were annealed at $500{ }^{\circ} \mathrm{C}$. Figure 2 shows the $M-H$ curves of these films. After annealing these samples, the coercive field became large (about $10 \mathrm{kOe}$ ) due to the $\mathrm{L}_{0}$ phase formation. All samples deposited on the amorphous $\mathrm{Al}_{2} \mathrm{O}_{3} / \mathrm{Si}$ substrate showed isotropic magnetic behavior. On the other hand, the films deposited on the $\mathrm{MgO}$ substrate still showed weak perpendicular anisotropy. Judging from these results, an orientation of the substrate seemed to affect the solid phase growth direction of the CoPt film [17]. Although $\mathrm{Au}$ is definitely
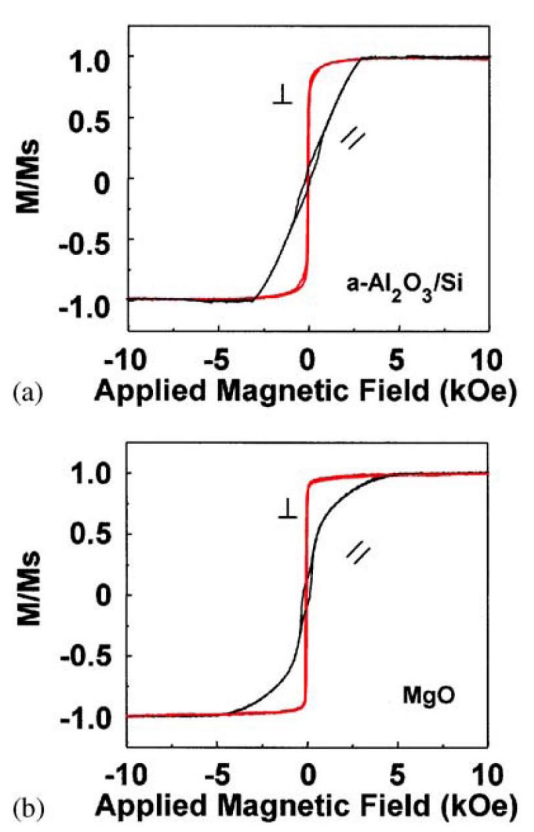

Figure 1. Magnetization curves of the $[\mathrm{Au} / \mathrm{CoPt} / \mathrm{Au}]$ film deposited at RT on (a) an amorphous $\mathrm{Al}_{2} \mathrm{O}_{3} / \mathrm{Si}$ substrate, and (b) a (l $\left.\begin{array}{lll}0 & 1\end{array}\right) \mathrm{MgO}$ substrate. 

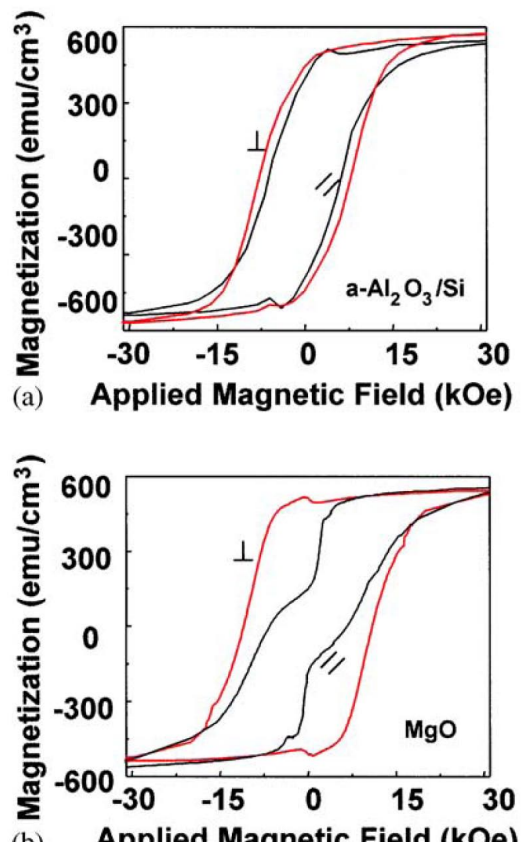

(b) Applied Magnetic Field (kOe)

Figure 2. $\mathrm{M}-\mathrm{H}$ curves of the $[\mathrm{Au} / \mathrm{CoPt} / \mathrm{Au}]$ film deposited on (a) an amorphous $\mathrm{Al}_{2} \mathrm{O}_{3} / \mathrm{Si}$ substrate and annealed at $500{ }^{\circ} \mathrm{C}(\mathrm{b})$ an $\mathrm{MgO}$ substrate and annealed at $500{ }^{\circ} \mathrm{C}$.

effective for the phase formation, a excess diffusion of Au seems to make the film magnetically isotropic. The high stability of the (1 111$)$ surface of $\mathrm{Au}$ on the $\mathrm{MgO}$ substrate [24, 25] might also cause the reduction in the perpendicular anisotropy. During the solid phase growing process of the CoPt film, some Au with (1 111 ) texture might have also been grown on the $\mathrm{MgO}$ substrate. The $\mathrm{Au}$ (1111) plane lattice is close to the CoPt (111) plane lattice. Although the (1 1 1) plane of FCC structure is the most stable plane, this might cause some CoPt to become a base for more (1 11 1) nucleation.

Because the crystal orientation of the initial layer is important for the growth direction of the film at a relatively high substrate temperature, we also investigated a growth behavior of the Au initial layer. The sample was prepared on an $\mathrm{MgO}$ substrate at $350{ }^{\circ} \mathrm{C}$, which is a starting temperature of $\mathrm{L}_{0}$ phase formation in this system. We expected that a film with $\mathrm{L1}_{0}$ phase, in which the growth direction was assisted by the orientation of an $\mathrm{MgO}$ substrate, was produced

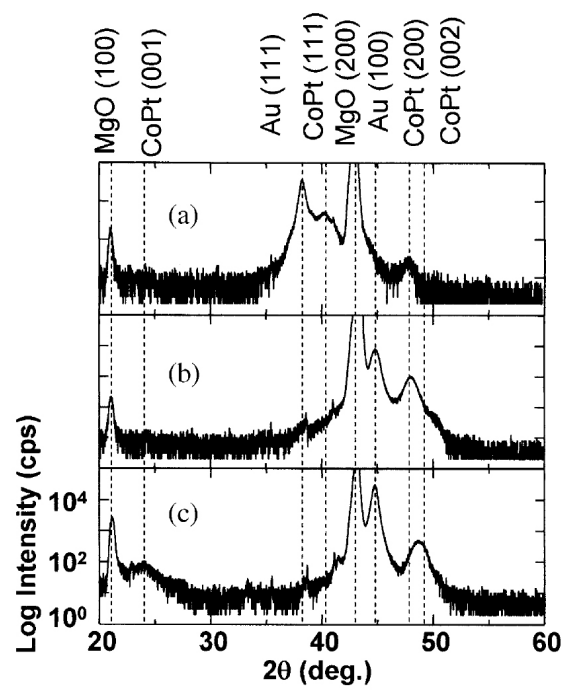

Figure 3. The X-ray diffraction patterns of (a) [Au/ $\mathrm{CoPt}$ film with $\mathrm{Au}$ initial layer deposited on $\mathrm{MgO}$ at $350{ }^{\circ} \mathrm{C}$ (b) [Au/CoPt] film deposited on $\mathrm{MgO}$ at $350^{\circ} \mathrm{C}$ without the Au initial layer (c) $[\mathrm{Au} / \mathrm{CoPt}]$ film without the $\mathrm{Au}$ initial layer deposited at $350{ }^{\circ} \mathrm{C}$ and annealed at $400{ }^{\circ} \mathrm{C}$.

[19]. Figure 3 shows XRD patterns of the [Au/ $\mathrm{CoPt}$ films deposited at $350^{\circ} \mathrm{C}$ (a) with and (b) without the initial $\mathrm{Au}$ layer. From the $-3.5 \%$ lattice mismatch between $\mathrm{Au}(4.06 \AA)$ and $\mathrm{MgO}$ $(4.21 \AA)$, we initially expected a $\left(\begin{array}{lll}1 & 0 & 0\end{array}\right)$ Au texture, but the sample with the $\mathrm{Au}$ initial layer shows a strong $(111) \mathrm{Au}\left(2 \theta=28.18^{\circ}\right)$ orientation due to the high stability of the (111) Au surface energy (Figure 3(a)). This can cause the [Au/CoPt] film also to have a (1 111 ) orientation. We have prepared a sample without the Au initial layer to investigate the effect of this layer. The sample without the Au initial layer (Figure 3(b)) has a $\left(\begin{array}{lll}0 & 0\end{array}\right)$ orientation. Especially in the [Au/ $\mathrm{CoPt}$ ] film the (l 002 ) diffraction, which is related to the FCT phase, is observed. This FCT phase is assumed to be constituted by both inter-diffusion of the Au during the deposition and assistance from the orientation of the $\mathrm{MgO}$ substrate. Furthermore, it is suggested that the initial CoPt layer behaves as a seed layer and the [Au/CoPt] film with FCT phase is grown by nucleation using this seed layer. The sample was annealed at $400{ }^{\circ} \mathrm{C}$ to produce a well-ordered crystal structure. This XRD pattern is shown in Figure 3(c). After annealing the sample, the intensity of the 


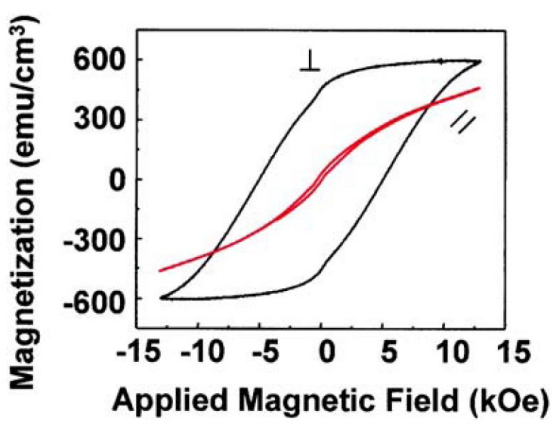

Figure 4. In-plane and out-of-plane $M-H$ curves of the $[\mathrm{Au} / \mathrm{CoPt}$ sample grown on the $\mathrm{MgO}$ substrate without the Au initial layer and annealed at $400^{\circ} \mathrm{C}$.

$\left(\begin{array}{lll}0 & 0 & 2\end{array}\right)$ diffraction peak became large and a $\left(\begin{array}{lll}0 & 0 & 1\end{array}\right)$ diffraction peak $\left(2 \theta=24.02^{\circ}\right)$ was observed. From the XRD patterns, we deduced the integrated intensity ratios $I_{(001)} / I_{(002)}$, and extracted the degree of long-range chemical ordering, $S . S$ is defined as the probability of correct site occupation in the $\mathrm{L}_{0}$ lattice, and is give by

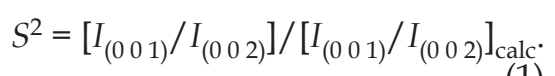

By taking the X-ray penetration depth [26] and Debye-Waller factor [27] into account, $\left[I_{\left(\begin{array}{lll}0 & 1\end{array}\right)} /\right.$ $\left.I_{\left(\begin{array}{ll}0 & 0\end{array}\right)}\right]_{\text {calc }}$ is calculated to be around 1.87 and $S$ is estimated to be about 0.71 [28], [29] and [30].

Figure 4 shows in-plane and out-of plane $M$ $H$ curves for the $[\mathrm{Au} / \mathrm{CoPt}$ ] sample grown on the $\mathrm{MgO}$ substrate without the Au initial layer. Strong perpendicular anisotropy was obtained in this film.

\section{Summary}

We investigated the magnetic anisotropy of a $\mathrm{CoPt} / \mathrm{Au}$ film with a low $\mathrm{Ll}_{0}$ phase formation temperature. Below the $\mathrm{L1}_{0}$ phase formation temperature, all the films have a perpendicular anisotropy irrespective of the kind of substrate. This behavior is due to the multi-layered structure. In order to get an $\mathrm{L} 1_{0}$ phase, samples were annealed at over $350{ }^{\circ} \mathrm{C}$. After annealing the samples, the magnetic anisotropy behavior was different for different substrates. The sample de- posited on the amorphous $\mathrm{Al}_{2} \mathrm{O}_{3} / \mathrm{Si}$ substrate shows isotropic magnetic behavior. On the other hand, although the perpendicular anisotropy behavior of the sample deposited on the $\mathrm{MgO}$ substrate became lessened, it still showed perpendicular anisotropy. The film without a $\mathrm{Au}$ initial layer deposited at $350^{\circ} \mathrm{C}$ has a $\left(\begin{array}{lll}0 & 0 & 1\end{array}\right)$ orientation. After annealing the sample at $400^{\circ} \mathrm{C}$, it showed strong perpendicular anisotropy and an $\mathrm{L1}_{0}$ phase with a coercivity of $6 \mathrm{kOe}$.

\section{Acknowledgements}

This research is supported by NSF MRSEC DMR0213808, W. M. Keck Foundation, Army Research Office DAAD 19-03-1-0298, INSIC, NRI and CMRA.

\section{References}

[1] E.S. Murdock, IEEE Trans. Magn. 28 (1992), p. 3078.

[2] K.R. Coffey, M.A. Parker and J.K. Howard, IEEE Trans. Magn. 31 (1995), p. 2737.

[3] S. Sun, C.B. Murray, D. Weller, L. Folks and A. Moser, Science 287 (2000), p. 1989.

[4] S.H. Liou and Y.D. Yao, J. Magn. Magn. Mater. 190 (1998), p. 130.

[5] A.S. Darling, Plat. Met. Rev. 7 (1963), p. 96.

[6] R.A. MacGuire and P. Gaunt, Philos. Mag. 13 (1966), p. 567.

[7] M.R. Visokay and R. Sinclair, Appl. Phys. Lett. 66 (1995), p. 1692.

[8] S. Stavroyianns, I. Panagiotopoulos, D. Niarchos, J.A. Chistodoulides, Y. Yang and G.C. Hadijipanayis, Appl. Phys. Lett. 73 (1999), p. 3453.

[9] V. Parasote, M.C. Cadeville, G. Garreau and E. Beaurepaire, J. Magn. Magn. Mater. 198-199 (1999), p. 375.

[10] R.F.C. Farrow, D. Weller, R.F. Marks, M.F. Toney, S. Hom, G.R. Harp and A. Cebollada, Appl. Phys. Lett. 69 (1996), p. 1166.

[11] C. Chen, O. Kitakami, S. Okamoto and Y. Shimada, Appl. Phys. Lett. 76 (2000), p. 3218.

[12] H. Yamaguchi, O. Kitakami, S. Okamoto, Y. Shimada, K. Oikawa and K. Fukamichi, Appl. Phys. Lett. 79 (2001), p. 2001. 
[13] O. Kitakami, Y. Shimada, K. Oikawa, H. Daimon and K. Fukamichi, Appl. Phys. Lett. 78 (2001), p. 1104.

[14] T. Maeda, T. Kai, A. Kikitsu, T. Nagase and J. Akiyama, Appl. Phys. Lett. 80 (2002), p. 2147.

[15] S.-R. Lee, S. Yang, Y.K. Kim and J.G. Na, Appl. Phys. Lett. 78 (2001), p. 4001.

[16] T. Yokota, L. Gao, S.H. Liou, M.L. Yan and D.J. Sellmyer, J. Appl. Phys. 95 (2004), p. 7270.

[17] B.M. Lairson, M.R. Visokay, E.E. Marinero, R. Sinclair and B.M. Clemens, J. Appl. Phys. 74 (1993), p. 1922.

[18] Z. Zhang, K. Kang and T. Suzuki, J. Appl. Phys. 93 (2003), p. 7163.

[19] O. Ersen, V. Parasote, V. Pierron-Bohnes, M.C. Cadeville and C. Ulhaq-Bouillet, J. Appl. Phys. 93 (2003), p. 2987.

[20] J.C.A. Huang, A.C. Hsu, Y.H. Lee, T.H. Wu and C.H. Lee, J. Appl. Phys. 85 (1999), p. 5977.

[21] C. Chappert and P. Bruno, J. Appl. Phys. 64 (1988), p. 5737.
[22] A.A. Kusov, S.S. Jaswal and Z.S. Shan, Phys. Rev. 46 (1992), p. 3123.

[23] F.J.A. den Broeder, D. Kuiper, A.P. van de Mosselaer and W. Hoving, J. Appl. Phys. 60 (1988), p. 2769.

[24] H. Sato and S. Shinozaki, J. Vac. Sci. Tech. 8 (1971), p. 159.

[25] H. Sato, S. Shinozaki and L.J. Cicotte, J. Vac. Sci. Tech. 6 (1969), p. 62.

[26] S. Okamoto, O. Kitakami and Y. Shimada, J. Magn. Magn. Mater. 208 (2000), p. 102.

[27] J.-U. Thiele, L. Folks, M.F. Toney and D.K. Weller, J. Appl. Phys. 84 (1998), p. 5686.

[28] B.E. Warren, X-ray Diffraction, Dover, New York, 1990, pp. 208-211.

[29] O. Kitakami, H. Sato, Y. Shimada, F. Sato and M. Tanaka, Phys. Rev. B 56 (1997), p. 13849.

[30] C. Chen, O. Kitakami, S. Sato and Y. Shimada, Appl. Phys. Lett. 76 (2000), p. 3218. 